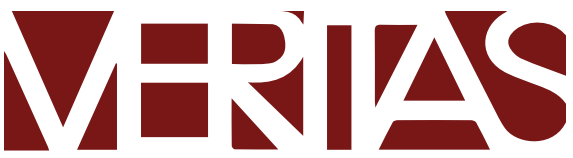

$\begin{array}{lllllllllll}P & O & R & T & O & A & L & E & G & R & E\end{array}$

http://dx.doi.org/10.15448/1984-6746.2019.2.33408

\title{
DIREITO, INTERSUBJETIVIDADE E ESTADO EM EDITH STEIN
}

\author{
Law, intersubjectivity and State in Edith Stein \\ Derecho, intersubjetividad y Estado en Edith Stein
}

Marcio Henrique Pereira Ponzilacqua'

Universidade de São Paulo, Ribeirão Preto, SP, Brasil.

\section{Resumo}

O objetivo do artigo é compreender e apresentar a filosofia do direito no âmbito do pensamento de Edith Stein. Sob o prisma fenomenológico, há de se analisar os conceitos axiais empregados pela autora, capazes de elucidar o sentido de direito, tais como Pessoa, Comunidade e Estado, conforme defluem de seus escritos e refletivos à luz de especialistas. Com base nesses elementos, há de se perscrutar a atualidade e aplicação do seu pensamento no contexto sociojurídico contemporâneo e as possíveis consequências desta aferição. Há também de se ponderar e refletir os paradigmas hegemônicos na ciência jurídica mediante às contribuições peculiares da autora. Os resultados da

\footnotetext{
1 Doutor em Política Social pela Universidade de Brasília (UnB), Mestre em Linguística pela Universidade Estadual Paulista (Unesp). Possui Livre-Docência em Sociologia do Direito, e pós-doutorado em Sociologia do Direito pela Universidade da Picardia, Amiens, França e Direito e Religião pela Universidade de Estrasburgo, França. Foi professor visitante na Universidade Católica de Louvain, Bélgica. É professor Associado da Faculdade de Direito de Ribeirão Preto (FDRP) da Universidade de São Paulo (USP). http://orcid.org/0000-0002-3494-6537. E-mail: marciorique@usp.br
} 
análise permitem entrever a densidade dos textos de Stein, cujos aportes filosóficos podem orientar hermenêutica jurídica consistente, mediante percepção metanormativa.

Palavras-chave: Edith Stein. Teoria do direito e da justiça. Estado. Pessoa. Comunidade.

\begin{abstract}
The objective of the article is to understand and present the Philosophy of Law within the thinking of Edith Stein. Under the phenomenological prism, axial concepts employed by the author, capable of elucidating the sense of law will be analyzed, such as Person, Community, and State, as they flow from his writings and reflective in the light of experts. Based on these elements, the relevance and application of their thinking in the contemporary socio-juridical context will be examined and the possible consequences of this assessment. It is also necessary to consider and reflect the hegemonic paradigms on legal science through the author's own contributions. The results of the analysis allow to glimpse the density of Stein's texts, whose philosophical contributions can guide consistent juridical hermeneutics through the metanormative perception.
\end{abstract}

Keywords: Edith Stein. Theory of law and justice. State. Person. Community.

\title{
Resumen
}

El propósito del artículo es entender y presentar la filosofía del derecho en el contexto del pensamiento de Edith Stein. Sob una perspectiva fenomenológica, la analize examina los conceptos empleados por la autora, capaces de aclarar el sentido de la ley, como Persona, Comunidad y Estado, como defluem de sus escritos y reflexiones a la luz de los expertos. Partiendo de estos elementos, se busca presentar la actualidad y la aplicación de su pensamiento en el contexto sociojurídico contemporáneo y las posibles consecuencias de esta medida. También hay de se considerar y reflexionar sobre los paradigmas hegemónicos en la ciencia jurídicas a través de las contribuciones peculiares de la autora. Los resultados del análisis nos permiten una visión de la densidad de los textos de Stein, cuya contribución filosófica pueden orientar una hermenéutica jurídica coherente, por medio de una percepción metanormativa.

Palabras clave: Edith Stein. Teoría del derecho y la justicia. Estado. Persona. Comunidad. 


\section{Introdução}

O escopo desta reflexão é perscrutar a filosofia de Edith Stein concernente às noções de direito e de intersubjetividade. Os termos estão vinculados, no âmbito do pensamento de Edith Stein, a outros conceitos axiais, tais como Empatia, Pessoa, Estado e Comunidade. Por essa razão a exposição desenvolver-se-á mediante a explicitação desses conceitos com base nos escritos da pensadora em cotejo com a hermenêutica fenomenológica, cujo método ela emprega.

Como procedimentos de análise, o enfoque será a investigação terminológica e semântica de textos selecionados de Edith Stein e, empós, buscar-se-á a sua aplicação no contexto sociojurídico brasileiro.

Comparece como avanço e ampliação de reflexões havidas anteriormente, quando nos deparamos com uma possível "filosofia" do direito em Edith Stein ${ }^{2}$. Ainda que não haja muitos escritos referentes à compreensão sociojurídica da autora e tampouco se verifique abordagem estrita da ciência do direito, nos moldes de uma perspectiva monográfica, e faltem fontes para investigação, maiormente em nosso vernáculo, o pouco material encontrado é bastante eloquente e precioso, à luz do desenvolvimento intelectual e existencial da autora e demonstram o percurso de uma possível "filosofia" do direito em Edith Stein.

Dos títulos analisados, especificamente da autora estudada, destacam-se aqui o segundo volume das Obras Completas, relacionado especificamente ao tema "Estado e Comunidade"; e a tradução espanhola de Zum Problem der Eifühlung, confrontada com o original ${ }^{3}$ - por julgarmos que se tratam de textos essenciais para a compreensão do direito e da

\footnotetext{
2 PONZILACQUA, M. H. P. Intersubjetividade e direito no século XXI: a contribuição de Simone Weil e Edith Stein. In: FURLAN, V. (org.). Sujeito no Direito: histórias e perspectivas para o século XXI. Curitiba: Editora CRV, 2012.

3 STEIN, E. Obras completas: Escritos filosóficos etapa fenomenológica. V. II. (F. J. Sancho, ocd et al., trad. J. Urkiza, ocd, rev.) Burgos: Editorial Monte Carmelo/ Vitória: Ediciones El Carmem: Editorial de Espiritualidade (original de 1922); 2005; id., Sobre el problema de La empatia. Madrid: Editorial Trotta, 2004; id. Zum Problem der Eifühlung, Inaugural dissertation, Halle: Buchdruckerei des Waisenhauses, 1917.
} 
intersubjetividade, que são os temas axiais de nossa abordagem. A análise ora apresentada observa percurso de certo modo centrífugo, cujo núcleo gravitacional é a inteligibilidade da terminologia e as noções centrais da própria filósofa, e que cresce em direção à compreensão e à leitura de seus discípulos e culmina, em termos abertos, para aplicação no contexto sociojurídico atual, do século XXI, a demonstrar a força e a atualidade da teoria desenvolvida por Stein.

\section{A perspectiva da subjetividade, empatia e intersubjetividade em Edith Stein}

Neste primeiro tópico, procuraremos desvendar a relação entre os conceitos fundamentais desenvolvidos por Stein e a sua pertinência no âmbito de uma análise filosófica e sociológica do direito.

Assim, o primeiro estágio de análise concerne à relação entre as noções do indivíduo, do ser e da pessoa presentes na obra da autora, que conferem sentido ao "sujeito" e, por consequência, aos termos correlatos: "subjetividade" e "intersubjetividade", presentes nesta abordagem.

No âmbito da fenomenologia, de cuja formação e militância Stein há de se nutrir, encontramos em Heidegger (2001). a terminologia aplicável à inteligibilidade "do ser" como Dasein. De sua origem alemã, o Dasein pode ser traduzido como o "ser-no-mundo" ou o "estar-no-mundo", ou literalmente, o "ser-aí": é o ser que se "presenta", em seu modo próprio de ser - e cujo desvendamento pressupõe tanto a sua manifestação concreta e objetiva, quanto a apreensão e desvendamento paulatino que dele deflui e que se abre ao sujeito cognoscente, em meio às névoas do conhecimento, na perspectiva de abertura de sentido - o que caracteriza o elemento subjetivo da abordagem fenomenológica ${ }^{4}$.

\footnotetext{
4 Heidegger, no âmbito de sua perspectiva fenomenológica e no que respeita à religião, busca imprimir neutralidade. Mais do que ateísmo militante, é espécie de ateísmo ou indiferentismo teológico para preservar a radicalidade perseguida na abordagem filosófica (HEIDEGGER, M. Sein
} 
Para o jovem Heidegger, com o qual Edith Stein conviveu, é preciso distinguir duas dimensões do ser: 1) aquela que é designada pelo caráter "ontológico", referente ao ser em si mesmo, que está na profundidade, para além do fenômeno e da aparência, 2) e o designado pelo caráter "ôntico", que respeita ao ente, enquanto manifestação fenomênica imediata, aparente. O ôntico, por dizer respeito à superficialidade sensível do fenômeno, embasa o senso comum. E ontológico, por sua vez, possibilita a compreensão fundamental, que atinge as raízes do fenômeno, para além do que a maioria não consegue divisar. A teologia, para Heidegger, se situa no polo ontológico, enquanto a filosofia respeita ao caráter ôntico ${ }^{5}$.

Para Stein, todavia, a expressão mais adequada ao ser humano é Pessoa. A sua compreensão fenomenológica evita, por um lado, a coisificação do ser, e, por outro, a sua abstração, como sugerem os sentidos constantes nos termos "eu", "sujeito", "alma" ou "pessoa". E parece superar até mesmo a bidimensionalidade ou ambiguidade fenomenológica de Heidegger, em modo integrativo.

Evidencie-se que a dimensão concreta da Pessoa não se reduz à "corporeidade espacial". Com efeito, "o 'estar-em' nada tem a ver com espacialidade. É um existencial, algo pertinente ao modo próprio do Dasein e independente da corporeidade espacial do corpo" (tradução e grifos nossos) 7 .

O estar-em equivale a um ocupar, que tem significados múltiplos: realizar, levar a cabo, procurar-se, temer. A aplicação da noção de Pessoa no sentido que lhe é atribuído pela fenomenologia da pensadora, evita, a um só tempo, os extremos da coisificação como a abstração do ser. "O

\footnotetext{
und Zeit. Tübingen: Niemeyer, 2001, p. 301; SERBAN, C. C. La phénomelogie de la vie religieuse du jeune Heidegger. Archives de Sciences Sociales des Religion. n. 171, jul./set. 2015, p. 218-219).

5 SERBAN, ibid., p. 211-229.

6 WIMMER, R. Vier jüdische philosophinnen: Rosa Luxemburg, Simone Weil, Edith Stein, Hannah Arendt. Tübingen: Attempo Verlag, 1991; PONZILACQUA, ibid., p. 31.

7 Do original: [...] el estar-en no tiene nada que ver com la espacialidad. Es un existencial, algo perteneciente a la manera de ser del Dasein como tal e independiente de la corporeidad epacial del cuerpo . STEIN, E. La filosofia existencial de Martin Heidegger. Apres. C. R. GUZMÁN; trad. R. M. S. Carbó. Madrid: Editorial Trotta, 2010. p. 31.
} 
equívoco do sujeito cognoscente está em tentar imprimir-lhe forma ou de buscar apreendê-lo, limitá-lo em suas categorias pré-conceptuais. Nisso subtrai-se a liberdade do ser. Ou seja, fica reduzida ou obstruída a 'rebeldia' da existência" (tradução nossa) ${ }^{8}$.

O conceito de Comunidade empregado por Stein deflui desta noção axial, que é "a" pessoa. O ser se compreende na relação: "ser-para". O "estar-no-mundo" implica interação, relação. Implica "coexistir-no-mundo" - o que reivindica proximidade e direcionalidade. A proximidade concerne à redução das distâncias com os elementos circundantes. A direcionalidade requer um direcionamento para o mundo circundante. Compõem-se assim "estar com", que é a essência do conceito de Comunidade9: "Ao Dasein pertence um coestar com outros entes que também têm a forma do Dasein. Não se trata de encontrar os outros sujeitos que estão aí, mas sim de um estar com eles que já se pressupõe ao travar conhecimento e compreender (ao fazer as "presentações"). À compreensão do ser do Dasein pertence o compreender a outros" (tradução nossa) ${ }^{10}$.

A insuficiência e precariedade são experimentadas pelo ser solitário, que se abre, intuitivamente, ao encontro, ao movimento que a impele ao outro, ao mundo exterior. $\mathrm{Na}$ ontologia da grande filósofa, o ser que se abre se transforma em dom e não posse ou poder. Abre-se para uma perspectiva transcendente. Sem isso, é impossível inteligir a constituição da pessoa e a liberdade humana". "O fenômeno associativo é empático, porquanto atinente à capacidade de captar a alteridade e, por conta disso, há de se expressar pela intersubjetividade e interobjetividade". Logo, não se centra nem na

\footnotetext{
8 PONZILACQUA, ibid., p. 31.

9 PONZILACQUA, ibid., p. 31.

10 Do original: Al Dasein pertenece un coestar com outros entes que también tienem la forma do Dasein. No se trata de hallar a los outros sujetos que están-ahí, sino de un estar com ellos que ya se pressupone en todo trabar conocimiento y compreender (al hacer las presentaciones). A la compreensión del ser deo Dasein pertenece el compreender a otros" (STEIN, 2010, p. 31).

$"$ GERL-FALKOVITZ, H. B. Uma pienezza che viene da altro. In: BELLO, A. A.; ALFIERI, F.; SHAHID, M. Edith Stein, Hedwig Conrad-Martius, Gerda Walther: fenomenologia della persona, della vita e della comunità. Bari: edizioni Giuseppe Laterza, 2001. p. 82-91.
} 
razão nem na matéria, mas na interação de ambas, conforme a proposta husserliana A alteridade como desvendamento do 'eu'" é um ato criativo e multidimensional (espírito-corpo-sentimentos-razão) que transcende o condicionamento e a limitação de que ressente o ser criado ${ }^{12}$.

A compreensão e o encontro do outro - a alteridade - é sempre limitada. Não se pode apreendê-lo essencialmente e plenamente. Outro permanece como inquietação, surpresa ou como descoberta. Para a pensadora, compreende algo que mantém um lastro a ser decifrado e até se resguarda a possibilidade do indecifrável. Sua essência ao mesmo tempo em que se manifesta, se oculta. Surpreende, portanto, e causa espanto e até horror. Aproxima-se assim da compreensão de Emmanuel Lévinas ${ }^{13}$. Mas a alteridade é sempre um plus, um devir, um reconhecer e descobrir contínuo, que importa transcendência, inclusive a si mesmo no outro ${ }^{14}$.

$\mathrm{Na}$ Comunidade, desdobra-se o espaço existencial de abertura ao outro - o indivíduo solipsista se abre e se deixa tocar pelo fluxo vital sem se tornar inerme a si mesmo. A intersubjetividade e interobjetividade implicam-se mutuamente. A conduta individual passa a ser orientada e orientadora da conduta comunitáriaํㅗ (PEZZELLA, 2008, p. 65-72). A vida é perpassada assim pela expressão comunitária. O ser existe não por si e em si mesmo, mas inserto em uma totalidade maior a compor a estrutura do ser humano ${ }^{16}$. A Comunidade, cujo fundamento essencial são os indivíduos, é tomada como

12 STEIN, E. Sobre el problema de la empatia. Madrid: Editorial Trotta, 2004, p. 19-55; BELLO, A. A. L'universo nella conscienza: introduzione alla fenomenologia di Edmund Husserl, Edith Stein, Hedwig-Conrad Martius. 2. ed. Pisa: Edizioni ETS, 2007, p. 140-143; PONZILACQUA, op. cit., p. 31-32.

13 DOUEK, S. S. Paul Ricoeur e Emmanuel Lévinas: um elegante desacordo. São Paulo: Loyola, 2011, p. 127-142.

14 STEIN, 2004, p. 75-107; PONZILACQUA, op. cit., p. 32.

15 STEIN, E. Introduzione alla filosofia. Trad. Agnes Bello. Roma: Cittá Nuova, 1998, 116; 167; PEZZELLA, A. M. Communità e Popolo. In: BELLO, A A; PEZZELLA, A M. Edith Stein: comunità e mondo della vita - società, diritto, religione. Città del Vaticano: Lateran University Press, 2008. p. 65-78

16 STEIN, E. La struttura della persona humana. Trad. Michele D'Ambra. Roma: Cittá Nuova, 2000, p. 185; D'AMBRA, M. Persona e comunità. In: BELLO, A. A.; PEZZELLA, ibid., p. 30. 
dimensão indissociável da Pessoa - noção cuja compreensão é elemento fundamental para o desvendamento do ser. A Comunidade é lugar de expressão do ser, em sua condição relacional. A família é o primeiro âmbito de experiência comunitária, em que o núcleo da pessoa pode emergir ${ }^{17}$.

A Comunidade tem seu fundamento essencial nos indivíduos, e as suas transformações são decorrentes das alterações vivenciadas e manifestadas pelos indivíduos que a compõem. Mas a Comunidade não pode ser concebida como simples justaposição ou combinação de indivíduos quais partes de uma totalidade. As pessoas, como pessoas individuais, são dotadas de vivências e capacidades psíquicas inconfundíveis e singulares, donde a Comunidade só pode ser concebida qual "confluência" de experiências comuns e como seu enriquecimento. A Comunidade implica noção de unidade, mas que compreende mais um sentido de fusão ou integração do que de monolitismo ou uniformidade. A Comunidade é fundamentada nas potencialidades e expressões existenciais dos indivíduos, mas igualmente é o seu fundamento: ou seja, ela se configura como solo fértil de expressões atuais e potenciais da energia vital de cada componente ${ }^{18}$.

Stein concebe outras possibilidades de atualidades da vida social em comum ou agrupamentos que não se confundem, em primeira instância, com a Comunidade. É o caso, por exemplo, da massa, cujo contágio transindividual favorece a emergência de uniformidade. No entanto, falta à massa alguns elementos imprescindíveis à noção de Comunidade. O mais importante deles é a ausência de uma unidade interior que a constitua como unidade viva e existencial. Há imitação e pressão, mas não há conexão espirituais e profundas: a experiência grupal na massa é apreendida de modo epidérmico e por mecanismos impulsivos, e de um nível psicológico que se encontra mais próximo da sugestão do que da

17 D'AMBRA, ibid., p. 31-37.

18 STEIN, 2005, p. 448-451. 
efetividade da ação. Pode desembocar em um impulso de atividade, mas não há fundamentação lógica que a sustente ${ }^{19}$.

A existência de motivações suficientes, explícitas e fundamentas constituem-se os elementos propulsores da Comunidade e da intersubjetividade ${ }^{20}$. Na massa, a subjetividade está ausente porque igualmente carente de motivações interiores e espirituais que se traduzam na experiência e manifestação da esseidade do sujeito agente - que concerne ao modo-humano-próprio-de-ser, em sua expressão originária.

A empatia é a base da vivência correspondente. Emerge uma vivência originária - que é eminentemente interativa - de uma vivência não originária - que é solipsista. A empatia resulta de uma "apreensão" - apreender o sentimento do outro - e, por via de consequência, de um consentir - conscientemente me disponho a sentir com, a alegrar-me com a alegria do outro, a congratular-me. Esse é o sentido positivo da empatia. Mas há igualmente o sentido negativo da empatia, quando há obstrução da vivência originária da empatia em razão de sua não realização em decorrência de alguma vivência momentânea ou por constituição ou traço da própria personalidade ${ }^{21}$.

$\mathrm{Na}$ Comunidade ambos os fluxos da empatia são verificados. Por certo que inexiste comunidade sem a empatia positiva. Deve prevalecer: empatizar e sentir com! O "eu" e o "tu" convergem no sentimento comum emergente da interação e integração, que se perfaz no "nós". A empatia enriquece o vivenciar e a reciprocidade ("eu" e "tu") e permite desvendar e incluir um "ele", também isolado ${ }^{22}$. Mas, igualmente, é preciso conceber o sentido da empatia negativa interveniente na Comunidade para acercar-se de seus antagonismos, paradoxos e resistências ${ }^{23}$.

\footnotetext{
19 Ibid., p. 451-454.

20 Id., op.cit., p. 457-463.

21 Id., 2004, p. 29-31.

22 STEIN, 2005, p. 34.

23 NISBET, Robert Alexander. Comunidade. In: Forachi, M. M.: MARTINS, J. S. Sociologia e Sociedade (leituras de introdução à Sociologia). Rio de Janeiro: LTC, 1998, p. 255-261; BUBER, M.
} 
Stein reconhece, por consequência, um vínculo inextrincável entre comunidade e indivíduo. A comunidade "demonstra ser dependente, em primeiro lugar da peculiaridade dos indivíduos", mas a recíproca é igualmente verdadeira: "o indivíduo, em seu caráter, está condicionado pela comunidade, porquanto o indivíduo é representante de um tipo, num sentido inteiramente novo que unicamente se compreende a partir da vida comunitária"24.

\section{A construção da subjetividade, da intersubjetividade e do direito na perspectiva da teoria do Estado de Edith Stein}

Há intensos mecanismos de contágio, transmissão, excitação ou estímulo presentes no meio comunitário que fomentam a abertura do indivíduo. Sua índole pessoal desenvolve-se mediante tais influências - o que não implica anular plenamente suas inclinações naturais. A responsabilidade individual mantém-se íntegra sob essa tensão, todavia. A unidade pretendida resulta em um jogo de desprendimentos, afirmações e transformações, que tocam ao indivíduo e à comunidade, ao ponto que se pode falar também de um "caráter, alma e espírito" da comunidade ${ }^{25}$. Os laços de união que justificam a vida comunitária, em última instância, devem ser encontrados na livre espiritualidade e originalidade, a imprimirem a qualidade de "personalidade responsável" à comunidade e aos indivíduos, sem o que não se pode conceber os vínculos comunitários como realidade supraindividual, unitária e "original"26.

No entanto, o impulso individual de viver plenamente sua vida não pode ser absorvido ou consumido plenamente pela comunidade - esse impulso pode transcender às necessidades da comunidade e, por vezes, pode restar pouco ou nada benéfico para a comunidade, ou, às vezes,

Sobre comunidade. Trad. Newton Aquiles von Zeuben. São Paulo: Ed. Perspectiva, 1987, p.106-107.

24 STEIN, 2005, p. 472-473.

25 Ibid., p. 272-484.

26 Ibid, p. 486. 
transformá-la gradativamente. Pode ocorrer o inverso: uma pessoa completamente dedicada à comunidade. Há, então, que se convir que a relação do indivíduo necessita ser uma relação viva - em que o fluxo comunicativo se estabeleça continuamente entre comunidade e pessoas, como um organismo em seus fluxos vitais. Tais elementos permitem compreender o que passaremos a expor a seguir: as relações existentes no âmbito de expressões comunitárias específicas, tais como Povo, Nação e Estado, em que as relações individuais ou pessoais com a estrutura comunitária desenvolvem em graus distintos de interação, mais ou menos estáveis e intensos, conforme o tipo abordado ${ }^{27 .}$

O sentimento de pertença e os níveis de conexão são variáveis nessas expressões relacionais ou comunitárias (Povo, Nação e Estado), e elas, em grande medida, explicam as normas reguladoras da convivência - com destaque para as formas de direito.

O conceito de Povo é consequência existencial da noção de Família e de Comunidade, porém menos intenso - mas bem mais intenso que o de Estado. A dupla pertença de Stein ao povo hebraico e alemão, e as agruras da perseguição semítica pelos nazistas, faz com que a filósofa reconheça que Povo e Estado não se confundem e a pertença à comunidade de um povo implica antes no engajamento ao seu desenvolvimento comunitário e à busca da construção de interesses comuns do que por vínculos de sangue, étnicos ou jurídicos. Ou seja, o vínculo de sangue ou étnico, ainda que possa fundar uma comunidade popular, não é pressuposto necessário. A comunhão espiritual é mais importante, e exemplifica como o povo hebraico, cujos vínculos afetivos, costumes, leis e tradições o constituíram como comunidade a preceder a emergência estatal. Acontece inclusive de o povo sobreviver ao Estado ou sem ele, no caso dos povos nômades - por conseguinte, Povo e Estado não se identificam a princípio ${ }^{28}$.

\footnotetext{
27 Id., op.cit., p. 487-491.

28 D'AMBRA, 2008, p. 38-41; STEIN, E. La struttura della persona humana. Trad. Michele D’Ambra. Roma: Cittá Nuova, 2000, p. 202-230.
} 
Ao conceber uma "comunidade estatal", Stein a percebe como tipo comunitário cujas relações são de várias categorias: supraordenadas e subordinadas a outras comunidades, a um só tempo, e, por vezes, também coordenadas. É dizer que a estatalidade implica na existência de uma comunidade suprema que subsiste nas comunidades as quais se vincula e, ao mesmo tempo, as fundamenta. Consiste em uma ampliação potencial das comunidades mais estritas e como sua atualização ${ }^{29}$. O específico da comunidade estatal se encontra na sua autossuficiência (autarquia) cujo equivalente moderno é a soberania. Isso implica que nenhum "poder exterior - seja indivíduo, ou uma comunidade supraordenada, coordenada ou subordinada - pode prescrever as formas de sua vida estatal" - cabe à comunidade estatal o "direito de legislar" por sua própria autoridade ${ }^{30}$.

Se houver um legislador que sobreponha à comunidade estatal resulta na perda da soberania, e, por consequência, da estatalidade. $O$ direito internacional ("direito das gentes") só comparece como limitante por vontade expressa do Estado, o que não equipara à perda de sua autonomia porquanto ele assume aquela disposição normativa no complexo de sua decisão legislativa associada à vontade espiritual da comunidade estatal.

A soberania importa a análise das conexões entre direito e Estado. Por se tratar do único poder legítimo para dispor de sua esfera de domínio, a soberania requer a Loyalität, no sentido que lhe atribui Johan Rudolf Kjellén, sociólogo sueco citado por Stein. A Loyalität equivale à existência de direitos e deveres presentes no todo estatal que imprimem lealdade. Quando se opõe à legalidade estatal e a personalidade do povo pode suceder que um ou ambos venham a sucumbir e perecer. No âmbito estatal podem coexistir distintas nações com distintas manifestações de direito, mas há que existir um vínculo de lealdade entre essas expressões de direito que configurem uma consciência coletiva, que é própria do povo. A Nação emerge como consciência reflexa e nisto se distingue do

\footnotetext{
29 STEIN, 2005, p. 531.

3o STEIN, ibid., p. 532.
} 
Povo. "O Estado exige como fundamento uma comunidade popular" - um povo - "e não uma nacionalidade" ${ }^{31}$. Inexiste comunidade estatal sem comunidade popular. Aquela se radica nesta. Povo e Nação constituem-se como comunidade eminentemente espiritual, mas a pensadora adverte para o risco de opor-se natureza e espírito. Na racionalidade peculiar que assiste à constituição do Povo, da Nação e do Estado comparecem imbricadas natureza e espírito, donde a autora fala de uma "natureza espiritual"32. Na democracia, todos os cidadãos são portadores teórica ou potencialmente da vida do Estado.

O conjunto normativo de uma comunidade estatal traduz valores comunitários e metaindividuais. Jamais uma comunidade estatal pode subsistir sem esse substrato valorativo metaindividuais. Os valores comunitários e os valores individuais e grupais pressupõem-se mutuamente. Há relações dialéticas, por vezes complementares, por vezes antagônicas entre os valores dos indivíduos e grupos e aqueles da comunidade.

Emerge, pois, a fenomenologia do direito de Stein. O direito positivo tem seu fundamento na pessoa enquanto intersubjetividade: “[...] um sujeito que tenha o poder de torná-lo vigente e uma pluralidade de pessoas as quais o direito se destine e que o reconheçam a ponto de positivá-lo, que compareçam como autor e destinatário" (tradução nossa) ${ }^{33}$ Portanto, o direito engendra-se na comunidade e para ela se destina, tanto como coletividade quanto às pessoas que a compõe. A Comunidade (Gemeinschaft), torna-se uma apriori, noção concreta e plural, espaço interacional e de communicatio. A Comunidade, em conjunto com a noção de Povo (Volksgeist), pressupõe elemento cultural a distinguir o direito

\footnotetext{
${ }^{31}$ STEIN, 2005, p. 541-542.

32 STEIN, ibid., p. 543-544; AVITABILE, L. II ruolo della comunità nella vita sociale, politica e religiosa. In: BELLO, A. A.; PEZZELLA, op. cit., p. 88.

33 Do original: [...] un soggetto che abbia il potere di renderlo vigente e una pluralità di persone alle quali il diritto sia destinadto e che lo risconoscano per renderlo appunto positum, quindi da una parte I"autore, dall'altra i destinatari delle norme" (AVITABILE, ibid., p. 88).
} 
positivo daquele que a autora considera o direito puro (as metanormas, o substrato valorativo a que deve reportar o direito).

Com efeito, Stein distingue duas noções fundamentais a elucidar a ideia de direito. A primeira, relativa às relações-de-direito "puras", corresponde a estados-de-cosas de direito que existem ou preexistem à margem de todo arbítrio e independem de reconhecimento por quaisquer modalidades de direito vigentes (e exemplifica: direito que nasce da promessa de pagamento, se extingue com o cumprimento da promessa ou é injusto deixar de pagar uma dívida); a segunda, o direito positivo, é justamente a seara do direito em vigor. Ele é arbitrário e se estabelece segundo conveniências. $O$ direito puro é o mesmo em todo tempo e em todos os povos. É perene. Poderíamos dizer, é metanormativo. A validade do direito é uma realidade temporal e circunscrita. Todavia, a pretensão de validade diz respeito a uma forma apriorística - a forma do direito comum ao direito puro e ao direito vigente. $O$ direito em vigor implica o reconhecimento estatal do direito de legislar, alguém que faça valer. As normas de direito puro precisam encontrar-se com a vontade do Estado em sua representação legislativa para serem validadas. Se não validadas no âmbito da consecução dos atos legislativos, há um desligamento entre o direito puro e o positivo34 (STEIN, 2005, p. 551-559).

Assim, o Estado como sujeito de direito, na perspectiva steinneana, tem sua gênese na "comunidade espiritual formada das relações interpessoais" que supõem, assim, empatia, comunicação e alteridade e, em última instância, radica-se na estrutura humana ontológica, capaz de apreender, escolher e se destinar a outro (tu). A autonomia e a soberania estatal defluem da sua gênese comunitária, razão por que sua capacidade criativa e reprodutiva se estabiliza e limita-se pela comunidade. Por sua vez, como antecipamos, a Comunidade remete, necessariamente ao tripé "pessoa-personalidade-soberania". Dessarte, só poderá se conceber a legitimidade e justificação

34 STEIN, 2005, p. 551-559. 
de um direito positivo em um direito puro, prévio, alicerçado em uma fenomenologia do Estado do ponto de vista axiológico. Ao Estado incumbe, mediante a ordem jurídica, prover à satisfação das dimensões ontológicas do humano ${ }^{35}$. O desvirtuamento dessa incumbência ou sua falibilidade, operados pelos seus dirigentes, implicam na distorção da própria essência do Estado e eventual perecimento comunitário - haja vista que está orientado precipuamente para o núcleo interior, isto é, ao benefício de todos e cada um de seus cidadãos. Suas atividades exteriores gravitam em torno do núcleo interior - como sua consolidação e ampliação ${ }^{36}$.

A interação entre valores e normas encontra-se no âmbito da dialogia, da alteridade e intersubjetividade. Ao Estado compete custodiar a realização dos valores que emergem desta dialogia, e isto se perfaz mediante um conjunto normativo. Edith Stein tem clareza sobre isso, mas reconhece a existência de uma hierarquia axiológica a presidir os valores sociais e políticos, sem o que a existência coletiva é impossível. Ela própria foi vítima da tragédia da inversão da escala axiológica, quando morreu no campo de concentração, tendo lucidez incomparável da sucessão dos acontecimentos sociais que a conduziriam à morte e da sorte dos semitas sob o espectro nazista37.

\section{A atualidade da reflexão de Edith Stein sobre o direito: os horizontes propostos}

Em tempos de contestação da obra monumental de edificação secular da defesa direitos humanos - expressão que não parece constar explicitamente na obra de Stein, mas cujo conteúdo ela prenuncia por sua vida e morte -, os textos da filósofa alemã, mártir da intolerância e do fascismo, abrem perspectivas inusitadas.

35 STEIN, E. Introduzione alla filosofia. Trad. Agnes Bello. Roma: Cittá Nuova, 1998, p 38; Id., Una ricerca sullo Stato. Trad. Agnes Bello. Roma: Cittá Nuova ,1999, p. 30-49 e 76ss.; AVITABILE, ibid., p. 79-117.

36 STEIN, 2005, p. 591.

37 STEIN, E. A ciência da cruz. São Paulo: Loyola, 2002, p. 154. 
Apontaremos cinco elementos que dela defluem e que podem propiciar hermenêutica jurídica consistente, heterorreflexiva e, ao mesmo tempo, suficientemente fundamentada a ponto de sustentar validez comunicativa e eficácia.

Os elementos destacados são: 1) fundamento metanormativo da verdade jurídica em vista da descoberta do chamado "direito puro"; 2) a relevância da "pessoa" ou "sujeito" nas representações sociais e como núcleo de compreensão das elaborações e normatizações comunitárias e estatais; 3) intersubjetividade: a norma posta como expressão de desenvolvimento comunicativo e elaboração comunitária, sobre as bases da dialogia e da alteridade; 4) compreensão, definição e transmissão de substrato e hierarquia axiológicos; e 5) a ordem jurídica estatal deve propiciar condições para a satisfação das dimensões ontológicas do humano.

1) Fundamento Metanormativo: o direito tem sua validez erigida em um ideal de direito, vale dizer, no direito puro, que difere, como elucidamos anteriormente, da teoria do direito puro positivista. Ao contrário, no âmbito da fenomenologia de Stein, haurir o direito puro parece significar aquele conjunto de pressupostos existentes para além da norma positivada, mas que subjazem a todo conjunto de normas pretendidas pelos diversos grupos sociais. É perscrutar os vínculos existenciais que possam configurar e embasar a linguagem do direito. É dizer: são os elementos metanormativos, consignados em ideais de justiça mais ou menos universais e atemporais que servem de sustentação para a elaboração dos respectivos ordenamentos jurídicos, esse sim, de matiz histórica e permeados das variáveis culturais. O fundamento normativo, que é a metanormatividade, encontra no núcleo da "esseidade" - a expressão e substância dos seres, seu eixo gravitacional, a fim de suplantar os contornos e limites históricos. Os direitos humanos na contemporaneidade foram edificados no sentido de servir de balizas metanormativas. Todavia, eles mesmos, enquan- 
to construções humanas e positivadas, estão sujeitos aos limites culturais, históricos e da geografia humana e política. A pretensão de Stein, é encontrar fontes mais perenes, mediante o aprofundamento do conhecimento ontológico, daquelas que são as bases de sustentação do direito, para além de suas formulações históricas. E no desvendamento do sentido apriorístico do direito, as duas chaves imprescindíveis de leitura são a Pessoa-Sujeito e a Comunidade, ambas como fonte e destinatários das normas. O direito puro é a dimensão ontológica do direito. Consiste nas suas raízes e profundezas. Enquanto o direito vigente corresponde à sua dimensão ôntica, aparente e superficial.

2) A relevância da "pessoa" ou "sujeito": neste afã de conceber a "metanormatividade", Stein não se refugia em uma abstração inconcebível, ou em uma lógica insustentável de rebuscamentos linguísticos nem em imagens hipotéticas. Ela encontra na "pessoa", a forma genuína de expressão do "ser", que se presenta, que gradativamente se conhece, mas que não se pode aprisionar, em virtude de sua liberdade genuína, indeclinável e fundante. A "pessoa", o "ser", a "alma" constituem o estado do vivente humano, que pode e deve se expandir em potencialidades e conhecimento em vista de seus destinos mais elevados. A Pessoa concebida na sua subjetividade, enquanto sujeito que livremente compreende, escolhe e aprimora, não pode ser reduzida a objeto. As elaborações jurídicas precisam comparecer como o modo de proteção e garantia dessa condição humana fundamental. Elas implicam intersubjetividade, ou seja, comunicação e dialogia em vista de compreensão das necessidades humanas da Pessoa e dos modos de assegurar o seu desenvolvimento adequado.

3) Intersubjetividade, desenvolvimento comunicativo e elaboração comunitária: a Comunidade comparece assim como o segundo eixo fundante do direito. A pessoa é o escopo e destino do direito. No entanto, as pessoas desenvolvem necessidades, 
expectativas e modos distintos de expressão. É na Comunidade, enquanto lugar de desenvolvimento da Pessoa, e não como aglomerado impositivo de padrões e condutas, que as normas de direito emergem. É dizer, requerem que o conjunto de indivíduos perscrutem e compreendam aqueles elementos fundamentais que são a base de sustentação do desenvolvimento e progresso sadio e adequado de todo o ser humano. Quando um ou outro grupo pretende detentor de expressão da verdade, solapam a verdade em si mesma, porque impedem o processo de aprimoramento comunicativo. Daí que a elaboração comunitária das normas de direito, no estágio da consignação de direitos e deveres expressos em normas escritas ou em costumes, exige constante dialogia e aprimoramento linguístico, sem que isso possa comparecer, como denuncia Bourdieu, nos rebuscamentos excludentes e aprisionantes da formalidade jurídica. Ao contrário, para Stein, trata-se de aprimoramentos linguísticos que se traduzem em clareza e aproximação das genuínas pretensões e necessidades dos sujeitos, em vista de seu desenvolvimento e amadurecimento, no sentido mais nobre e adequado da palavra. O direito puro e o direito vigente se consubstanciam e se encontram na forma jurídica. E, para isso, é fundamental a preservação da liberdade e dos contextos livres de opressão ou manipulação. Os regimes inclinados aos totalitarismos ou fascismos tentam a todo custo censurar as pretensões livres da expressão humana, o que implica a distorção do sentido de "pessoa" ou de humano defendidos por Stein. Os discursos de intolerância e de ódio, as pretensões mortíferas contra antagonistas e opressores vão no caminho inverso da dialogia e comprometem radicalmente a alteridade. E são crescentes nos contextos sociais e políticos polarizados hodiernos. Quaisquer imposições de grupos ou pessoas de modos de pensar e conceber as leis equivalem a subjugação humana e a desconsideração profunda da sua liberdade essencial. A intersubjetividade é desafio que se constrói em comunidades sustentadas pelo reconhecimento recíproco e pela alteridade, cuja base intransponível é o reconhecimento do outro/outra. 
4) Substrato e Hierarquia Axiológicos: neste estágio de amadurecimento comunitário é possível falar em emergência de valores. A Comunidade madura, constituída de sujeitos livres, é capaz de explicitar o que lhe é caro, o que vale para a sua própria manutenção e sobrevivência. É capaz de explicitar valores e transmiti-los mediante modos autênticos de comunicação, vale dizer, isentos de opressão ou manipulação. E ao explicitar os valores, é igualmente competente para, mediante processos argumentativos e linguísticos claros e participativos, envolver os demais na escolha dos valores e estabelecer escalas daqueles que são mais importantes, e precisam ser defendidos sobremaneira, e os que são transigíveis ou até cambiáveis. Nas sociedades plurais como as que vivemos, esse processo envolve muitas pessoas e comunidades, pelo que se tornam ainda mais exigentes e desafiantes. É imprescindível a construção de espaços comunicativos - ou pontes - em que os pontos de vista sejam livremente expostos e livremente adotados, mas sob a égide do bem comum, sem a qual a dialogia não se sustenta. Apresenta-se, assim, os primeiros valores a serem defendidos e protegidos, quer seja a vida, a liberdade, o bem comum, sem as quais nenhuma sobrevivência comunitária é edificável.

5) A comunidade estatal e a satisfação das dimensões ontológicas humanas: como explicitado, para Stein, a comunidade estatal é concebida como vinculada à comunidade popular, a um "povo", cujo sentimento de pertença e de participação estão vivos. A comunidade popular pode prescindir do Estado. Mas não o contrário. Enquanto Comunidade, o Estado preserva e protege valores individuais e metaindividuais. Precisa, nos casos de antagonismos, selecionar e privilegiar os valores que propiciem maiores condições de desenvolvimento das várias dimensões humanas, quer espirituais, quer materiais (liberdade de convicção e crença, possibilidades de vida digna, condições de desenvolvimento espiritual e intelectual, condições materiais de existência, de desenvolvimento e cuidado físicos). Nesse ponto, Stein como que se antecipa a uma doutrina e teoria 
dos direitos humanos. Cabe sobretudo ao Estado permitir que as diversas dimensões do modo próprio de ser humanos se aprimorem e desenvolvam adequadamente, garantindo-se os meios necessários para esse aprimoramento. As autoridades constituídas não podem impor normas contrárias a esse desenvolvimento nem solapar as liberdades dos indivíduos e suas comunidades. Pode, por vezes, exigir em termos sensatos, renúncias em vista do bem comum, mas sempre privilegiando os valores que possam servir a todos ou ao maior número possível de pessoas envolvidas naquela comunidade. E essas prerrogativas do Estado, em estabelecer uma ordem jurídica em que se prescrevem direitos e deveres, está sempre remetida e radicada na ontologia humana e na comunidade popular que o legitima. Tudo que se indispor contra a existência humana e o seu pleno desenvolvimento não pode ser concebido como valor metaindividual a ser positivado em normas jurídicas e não está legitimado. A soberania do estado decorre da soberania popular, de cuja referência aquela depende.

\section{Ciência do direito, paradigmas e ponderações à luz de Stein}

A filosofia do direito de Edith Stein propicia a reflexão e ponderação de paradigmas assentados no âmbito da ciência do direito. Haja vista sua inserção fenomenológica, a autora centra-se na consideração do sentido da manifestação fenomênica. Implica trazer à luz da consciência do sujeito cognoscente o objeto cognoscível ou que se pretende apreender. Assim, a compreensão do fenômeno se dá pela atenção ao sentido, que é eminentemente interativo, isso é, implica a relação transformadora do sujeito com o objeto que se revela gradativamente como dimensão da consciência.

A compreensão do termo fenômeno propicia a elucidação da fenomenologia. O vocábulo fenômeno expressa "o que se revela ou se faz patente por si mesmo", o que só é possível "a uma luz". Segundo 
Heidegger ${ }^{38}$ indica aquilo que "se revela por si mesmo na sua luz". Implica a suspensão fenomenológica, ou epoché husserliana, que corresponde a deixar que o fenômeno se manifeste. A epoché indica "certa suspensão do julgamento que se compõe com uma persuasão da verdade que permanece inabalada" ${ }^{39}$. Emerge do encontro da consciência com a coisa, pela busca de evidências, não meramente físicas, palpáveis, matemáticas e objetivas, mas compõem-se igualmente de vivências e experiências, que se revelam à consciência ${ }^{40}$.

A proposta fenomenológica distingue-se e ultrapassa a chamada "ciência pura do direito" proposta pelo positivismo jurídico, iniciado por Hans Kelsen ${ }^{41}$. Para a filósofa, embora o Estado, enquanto comunidade sui generis, tenha legitimidade para a construção da ordem jurídica positiva e tenha legitimidade para legislar, a validez do direito o ultrapassa e antecede. O Estado reflete e se submete aos valores da comunidade popular que o engendra, justifica e legitima. É a comunidade popular que imprime sentido ao direito estatal, ampliando-o ou limitando-o. A consciência individual e coletiva que permitem a apreensão do "direito puro" em Stein tem sofisticações metanormativas. Implica estado de consciência e vontade que não parecem presentes na teoria de Kelsen e dos demais positivistas. 0 direito, em última instância, não se reduz à norma, nem enquanto objeto, como defendido por Kelsen e o positivismo, nem enquanto fato meramente histórico e político - ideia também repelida pelos positivistas. Para a perspectiva defendida por Stein, o direito invoca a elaboração comunitária

\footnotetext{
38 HEIDEGGER, M. Ser e tempo. 4. ed. Trad. de Márcia S. Cavalcante. Petrópolis: Vozes, 1996 39 HUSSERL, E. Idées directrices pour une phénoménologie. Trad. P. Ricoeur. Paris: TEL-Gallimard, 1991. Tomo 1: Introduction générale à la phénoménologie, p. 100.

40 PONZILACQUA, M. H. P. Sociologia Ambiental do Direito: análise sociojurídica, complexidade ambiental e intersubjetividade. Petrópolis: Vozes, 2015, p. 88; BARREIRA, C. R. A. Análise fenomenológica aplicada à Psicologia: recursos operacionais para pesquisa empírica. In: MAHFOUD; M.; SAVIAN FILHO, J. Diálogos com Edith Stein. Filosofia, Psicologia e Educação. São Paulo: Paulus, 2017, p. 317-368.

${ }^{41}$ KELSEN, H. Teoria pura do direito. 2. ed. Trad. João Baptista Machado. São Paulo: Martins Fontes, 1987, p. 5-7; Teoria pura do direito. 5. ed. rev. Trad. José Cretella Júnior e Agnes Cretella. São Paulo: Revista dos Tribunais, 2007, p. 94.
} 
e os pressupostos existenciais decorrentes da compreensão da Pessoa e da Comunidade. Nelas o direito se alicerça e recobra sentido. Para Kelsen, Estado e direito se validam reciprocamente e, em larga medida, não há que se cogitar a "distinção entre direito e Estado, entre, portanto, teoria do direito e teoria do Estado, por ser o Estado a personificação da ordem jurídica coativa, 'ponto de imputação' de atos e de efeitos jurídicos [...]"42. O direito na perspectiva positivista é compreendido em um autorreferenciamento recursivo e se prende a um esforço de justificação e validação à descoberta do imediato e de evidências 'incontestáveis' de racionalidade lógica e científica. Logo, desconsidera a epoché, cara à fenomenologia, cujo sentido é decorrente da abstração derivada da consciência intencional, tensionada em direção à "coisa", ao "fenômeno"43.

A abordagem fenomenológica preserva a heterorreflexividade combatida e desdenhada por Kelsen no afã de construir uma teoria pura da ciência do direito. O contrário é destituir o direito de sua essencialidade fenomênica e assumir aquilo que lhe é periférico, ou superficial ${ }^{44}$. No positivismo, perdem-se os substratos vivenciais, cujo universo da consciência é o elemento distintivo da fenomenologia proposta por Husserl ${ }^{45}$, que Stein adota, aplica e sobre a qual cria pensamento peculiar. A autopoiesis - dinâmica criativa - do sistema do direito implica a possibilidade de comunicação com os outros sistemas e vivências localizados no exterior ${ }^{46}$,

42 GUSMÃO, P. D. Filosofia do Direito. Rio de Janeiro: Forense, 2008, p. 168.

43 MARTINI, R. S. A fenomenologia e a epoché. Trans/Form/Ação, São Paulo, 21/22: p. 43-51, 1998/1999; BARREIRA, loc. cit.

44 Justamente aquilo que a compreensão da "juridicidade" em Kelsen almeja, mas alcança de modo parcial. Cf. SGARBI, A. Clássicos de teoria do direito. 2. ed. rev. ampl. Rio de Janeiro: Lumen luris, 2009, p. 37-40.

45 HUSSERL, Edmund. Formal and transcendental logic. Trad. Dorion Cairns. The Hague: Martinus Nijhoff, 2010; Id. La philosophie comme science rigoureuse._4. ed. Trad. e apres. Marc B. de Launay. Paris: Presses Universitaires de France, 2009; BELLO, A. A. L'universo nella conscienza: introduzione alla fenomenologia di Edmund Husserl, Edith Stein, Hedwig-Conrad Martius. 2. ed. Pisa: Edizioni ETS, 2007.

46 CARNEIRO, W. A. Hermenêutica Jurídica Heterorreflexiva: uma teoria dialógica do direito. Porto Alegre: Livraria do Advogado, 2011, p. 161 
que o transformam e propulsionam. Ocorre com a elaboração coletiva do sistema jurídico movimento semelhante ao que sucede com a "empatia" em relação ao sujeito: a pessoa só pode descobrir-se profundamente pela dinâmica da alteridade. São os vários elementos da experiência humana, desvendados pelo universo da consciência coletiva e comunitária, que possibilitam a dinamicidade do sistema jurídico, o que impede que seja algo hermeticamente fechado. Nestas experiências estão incluídas as dimensões políticas, sociais, morais e culturais, não apenas como fatos exteriores, mas como expressões do modo de ser.

Outro contraponto possível a que a filosofia de Stein enseja é aquela da corrente marxista. Ao conceber o direito como elemento eminentemente superestrutural, em que os apelos da consciência são condensados sob a égide ideológica, Marx ${ }^{47}$ e os marxistas colocam-se em hermenêutica histórica e sociojurídica notadamente distinta de Stein. Para Marx, ainda que haja possibilidades de emergência de formas de direito provenientes da anarquia infraestrutural, e em algum sentido revolucionárias por contrapor-se ao direito enquanto expressão de domínio e controle das classes burguesas, a regra é que as normas jurídicas e a sua interpretação se dirijam à perpetuação dos elementos de dominação. O sentido do direito não é aquele explicitado na norma, mas aquele que ela oculta, dissimula e cujo eixo fundamental é valorado pela economia, decorrente noção de propriedade individual ${ }^{48}$. O direito anárquico e "revolucionário" apenas comparece como concessões ou tensões antagônicas de "direito contra direito" no âmbito da sistemática de poder e subjugação vigentes nos modos de produção capitalista. $O$ direito, a cultura e as doutrinas religiosas serviriam antes para reforçar os padrões de controle e de opressão dos sistemas econômicos vigentes e, ao mesmo tempo, favorecer o estatuto

\footnotetext{
47 MARX, 2006; MORAIS, L. F. L. Marx e o Direito. In: LEMOS FILHO, Arnaldo et al. Sociologia geral e do direito. 4. ed. Campinas: Alínea, 2009. p. 125-131.

48 ; LYRA FILHO, R. Karl, meu amigo: diálogo com Marx sobre o direito. Porto Alegre: Instituto dos Advogados do Rio Grande do Sul, 1983; PONZILACQUA, 2015, p. 92.
} 
e as divisões sociais imperantes. Stein não demonstra ter essa perspectiva eminentemente negativa. Ao não reduzir o direito à norma posta, mas que deve ser expressão da metanormatividade centrada na pessoa e na intersubjetividade, Stein entende o direito para além das configurações de dominação ou pelo menos como expressão de consciências individuais e coletivas que não se reduzem ao positivado.

O fato de Stein invocar a metanormatividade como elemento essencial do fenômeno jurídico, possibilita uma abertura, que longe de excluir as conflitividades tão caras ao marxismo, apenas evita tomá-las como elemento caracterizador do fenômeno, mas como expressões contingentes ou acidentais, e que podem ser superadas e combatidas mediante o reconhecimento do modo de ser que as orienta, que, em última análise é concernente à Pessoa e à intersubjetividade que a informa. Ao mesmo tempo, em Stein preserva-se a liberdade fundamental humana, em sua capacidade e possibilidade de sempre se reorientar e escolher o bem. No marxismo, a suplantação das estruturas econômicas de opressão poderia possibilitar a emergência e a permanência de expressões de igualdade social, garantidos por estruturas de poder revolucionárias. Todavia, escapa-lhe um elemento preponderante (que não escapa à filósofa Stein) que é a de que as estruturas permanentes ainda que favorecedoras de condições igualitárias só sejam boas se derivadas de escolhas individuais e coletivas igualmente permanentes, o que implica exercício e amadurecimento contínuo da liberdade. O humano precisa sempre ser seduzido e orientado para o bem. Estruturas sociais e jurídicas que venham a tolher a liberdade não podem ser boas em si mesmas, ainda que garantidoras de certa isonomia, pois desconstitutivas de elemento essencial do modo humano de ser, que é justamente a liberdade ${ }^{49}$. Em suprimindo-a, assola-se a dignidade humana.

De modo semelhante, a filosofia de Stein permite a ponderação de outros paradigmas eivados de considerável grau de historicismo ou relati-

49 "A liberdade deve ser sempre conquistada para o bem. A livre adesão ao bem nunca acontece por si mesma" (BENTO XVI. Carta encíclica Spes Salvi. 4. ed. São Paulo: Paulinas, 2008) 
vismo. É o caso de vertentes significativas do culturalismo ou do realismo jurídico. $\mathrm{O}$ culturalismo ${ }^{50}$ centra-se na concepção do direito como resultante dos processos históricos, enquanto o realismo ${ }^{51}$ oferece a ideia do direito como manifestação singular da interpretação concreta e realizável com base na força decisional do magistrado ou do sistema de justiça. Em última instância, o direito é aquilo que decide o juiz, não é a norma posta, mas a forma em que se realizada praticamente a partir do momento decisional.

A pensadora reconhece a constituição histórica do direito, mediante a elaboração contingencial do direito positivo, que é marcada pelo tempo e lugar. Mas ao propor a concepção de direito puro, que é eminentemente translocal e com razoável grau de atemporalidade, ela não o reduz o direito exclusivamente a produto de cultura determinada ou como expressão unicamente histórica, e tampouco ao direito oriundo da comunidade estatal. O direito, para conectar-se aos valores de justiça, precisa de bases que transcendam ao relativismo histórico ou a apreciação particularizada realizada por um juiz particular ou tribunal. São as bases axiológicas e de expressão comunitária, com razoável grau de permanência, que legitimam o direito e o orientam.

Há, contudo, a vertente culturalista defendida por Max Mayer cujo conteúdo parece dialogar com o pensamento de Stein ao compreender a cultura como interação da realidade com o valor: "a cultura não é somente realidade nem somente valor, mas sim a unidade de uma e de outra. A cultura é uma realidade transformada em realidade valiosa, um valor convertido em real" ${ }^{2}$. O Logos - entendido como o princípio sintético ou o pensamento supremo como razão última de toda ordem jurídica, é

\footnotetext{
50 REALE, M. Fundamentos do Direito. 4. ed. São Paulo: Migalhas, 2014, p. 239.

51 DUXBURY, N. Jerome Frank and the legacy of legal realism. Journal of Law and Society, $v$. 18, n. 2, p. 175-180, Summer 1991; RIBEIRO, F. T. C.; CAVALCANTE, H. C. O realismo jurídico. Associação dos Magistrados da Justiça do Trabalho; Universidade Federal do Sergipe. Disponível em: amatra19.org.br/artigos_/henrique_cavalcante/007.pdf. Acesso em: 11 ago. 2012.

52 MAYER, M. E. Filosofia del derecho. Trad. Luiz L. Lacambra. Barcelona: Editoral Labor, 1937, p. 156 , nota.
} 
a Justiça. Nela o sistema de justiça encontra sua validação e a expressão de sentido que o orienta ${ }^{53}$.

Destarte, o culturalismo e o realismo também podem ser arguidos, problematizados ou, ao menos, ponderados significativamente com base nas elaborações filosóficas de Stein.

As concepções positivista, marxista, culturalista e realista, com sua força persuasiva e de razão, são relevantes e podem ser empregadas nas análises sociojurídicas. Todavia, ao interpretar o direito como expressões de cultura ou até mesmo explicitar os mecanismos de embate por dizer o direito, que efetivamente ocorrem e que descrevem partes significativas do saber e fazer da ciência do direito, não alcançam sua complexidade fenomênica. A filosofia de Stein comparece como contraponto ponderável a matizar e a beneficiar não só a crítica como também aplicação desses mesmos paradigmas. Permite aproveitar o que descrevem do direito e dos quadros sociais que o engendram, mas estabelecendo-se, ao mesmo tempo, horizontes substanciais e equilibrados, porquanto manifestam a parcialidade dos pontos de vistas em que se centram os paradigmas hegemônicos.

\section{Considerações finais}

A "filosofia" do direito de Edith Stein é bastante atual. Por certo que há alguns elementos de sua teoria que não podem simplesmente ser transposto para o nosso tempo, sem as devidas complementações teóricas e com a elucidação das marcas temporais e de contexto. É o caso dos avanços havidos na doutrina da soberania estatal e sua relação com os ordenamentos internos - sobretudo em contextos de internacionalização. Mas é impressionante a sua acuidade e antevisão. Ao mesmo tempo, a sua fenomenologia existencial permite ponderar paradigmas consolidados na ciência do direito.

Distingue-se claramente da ciência pura do direito proposta pelo também pensador alemão, Hans Kelsen, que exclui de sua atenção a

53 REALE, M. Fundamentos do Direito. 4. ed. São Paulo: Migalhas, 2014, p. 257-258. 
norma como fato da consciência e tampouco atenta para a vontade ou a representação que lhe subjaz.

Distingue-se igualmente da perspectiva crítica engendrada com Marx, que entende o direito como elemento superestrutural e predominantemente como substrato ideológico da estrutura societária desigual. A forma jurídica, em última análise, é reduzida a expressão de dominação. Distingue-se do realismo jurídico, em cuja concepção, a despeito de seus diversos matizes, o direito é basicamente concebido como expressão da interpretação concreta e realizável na força executória da decisão judicial (o direito é, em última instância, aquilo que decide o juiz).

O culturalismo é igualmente contraposto pela teoria do direito puro de Stein. A compreensão de Stein pode iluminar essas perspectivas e, por vezes, destroná-las na medida em que distingue um conjunto metanormativo a presidir as escolhas comunitárias e que é engendrado na intersubjetividade - o direito puro - e que não se restringe nem se reduz ao direito positivo. Ele é o substrato profundo e as raízes mesmas do direito e permite desvencilhar as formas contingentes de elementos transcendentais apriorísticos capazes de orientar as escolhas coletivas.

A fenomenologia existencial de Stein permite conceber um direito de base axiológica comum e, ao mesmo tempo, suficientemente autônomo, resultante de integrações plurais e culturais, mas sempre atento à liberdade originária que o justifica e assiste, sem o que se torna irresponsável e despido de força persuasiva e contagiante, porque desprovido da dimensão coexistencial do modo-humano-próprio-de-ser.

\section{Referências}

AVITABILE, L. Il ruolo della comunità nella vita sociale, politica e religiosa. In: BELLO, Angela Ales; PEZZELLA, A. M. Edith Stein: comunità e mondo della vita - società, diritto, religione. Città del Vaticano: Lateran University Press, 2008.

BARREIRA, Cristiano Roque Antunes. Análise fenomenológica aplicada à Psicologia: recursos operacionais para pesquisa empírica. In: MAHFOUD, 
Miguel; SAVIAN FILHO, Juvenal (org.). Diálogos com Edith Stein: filosofia, psicologia e educação. São Paulo: Paulus, 2017. p. 317-368.

BELLO, Angela Ales. L'universo nella conscienza: introduzione alla fenomenologia di Edmund Husserl, Edith Stein, Hedwig Conrad-Martius. 2. ed. Pisa: ETS, 2007.

BUBER, Martin. Sobre comunidade. Tradução Newton Aquiles von Zeuben. São Paulo: Perspectiva, 1987

CARNEIRO, Wálber Araujo. Hermenêutica jurídica heterorreflexiva: uma teoria dialógica do direito. Porto Alegre: Livraria do Advogado, 2011.

CESTARI, Roberto Tagliari. Decisão judicial e realismo jurídico: evolução das pesquisas sobre o comportamento judicial. 2016. Dissertação (Mestrado em Direito) - Programa de Pós-Graduação em Direito, Faculdade de Direito, Universidade de São Paulo, Ribeirão Preto, 2016.

D'AMBRA, Michele. Edith Stein: uma fenomenologia dell' esistenza. In: BELLO, Angela Ales. L'universo nella conscienza: introduzione a la fenomenologia di Edmund Husserl, Edith Stein, Hedwig Conrad-Martius. 2. ed. Pisa: ETS, 2007. p. 439-478.

DOUEK, Sybil Safdie. Paul Ricoeur e Emmanuel Levinas: um elegante desacordo. São Paulo: Loyola, 2011.

DUXBURY, Neil. Jerome Frank and the legacy of legal realism. Journal of Law and Society, [s. l.], v. 18, n. 2, p. 175-205, 1991. https://doi.org/10.2307/1410136 GUSMÃO, Paulo Dourado de. Filosofia do direito. 9. ed. Rio de Janeiro: Forense, 2008.

GERL-FALKOVITZ, H. B. Uma pienezza che viene da altro. In: BELLO, Angela Ales; ALFIERI, F.; SHAHID, M. Edith Stein, Hedwig Conrad-Martius, Gerda Walther: fenomenologia della persona, della vita e della comunità. Bari: Giuseppe Laterza, 2011.

HEIDEGGER, Martin. Ser e tempo. 4. ed. Tradução Márcia S. Cavalcante. Petrópolis: Vozes, 1996.

HUSSERL, Edmund. Formal and transcendental logic. Tradução Dorion Cairns. The Hague: Martinus Nijhoff, 2010.

HUSSERL, Edmund. Idées directrices pour une phénoménologie. Tradução P. Ricoeur. Paris: TEL-Gallimard, 1991. (Introduction Générale à la Phénoménologie, t. 1). 
HUSSERL, Edmund. La philosophie comme science rigoureuse._4. ed. Tradução Marc B. de Launay. Paris: Presses Universitaires de France, 2009.

KELSEN, Hans. Teoria pura do direito. 2. ed. Tradução João Baptista Machado. São Paulo: Martins Fontes, 1987

KELSEN, Hans. Teoria pura do direito. 5. ed. Tradução José Cretella Júnior e Agnes Cretella. São Paulo: Revista dos Tribunais, 2007.

MACINTYRE, Alasdair. Edith Stein: a philosophical prologue 1913-1922. Lanhan: Rowman \& Littlefield Publishers, 2007.

MARTINI, Renato da S. A fenomenologia e a epochê. Trans/Form/Ação, Marília, v. 21-22, n. 1, p. 43-51, 1999. https://doi.org/10.1590/S0101-31731999000100006 MARX, Karl. Crítica da filosofia do direito de Hegel (1843). Tradução Rubens Enderle e Leonardo de Deus. São Paulo: Boitempo, 2006.

MORAIS, Luis Fernando Lobão. Marx e o direito. In: LEMOS FILHO, Arnaldo et al (ed.). Sociologia geral e do direito. 4. ed. Campinas: Alínea, 2009.

NISBET, Robert A. Comunidade. In: FORACHI, Marialice Mencarini; MARTINS, José de Souza. Sociologia e Sociedade: leituras de introdução à Sociologia. Rio de Janeiro: LTC, 1998. p. 255-261.

PEZZELLA, A. M. Communità e popolo. In: BELLO, Angela Ales; PEZZELLA, A. M. Edith Stein: comunità e mondo della vita - società, diritto, religione. Città del Vaticano: Lateran University Press, 2008. p. 79-130.

PONZILACQUA, Márcio Henrique Pereira. Intersubjetividade e direito no século XXI: a contribuição de Simone Weil e Edith Stein. In: FURLAN, Valéria (org.). Sujeito no direito: histórias e perspectivas para o século XXI. Curitiba: CRV, 2012. p. 29-44.

PONZILACQUA, Márcio Henrique Pereira. Sociologia ambiental do direito: análise sociojurídica, complexidade ambiental e intersubjetividade. Petrópolis: Vozes, 2015.

SGARBI, Adrian. Clássicos de teoria do direito. 2. ed. Rio de Janeiro: Lumen Juris, 2009.

STEIN, Edith. A ciência da cruz. São Paulo: Loyola, 2002.

STEIN, Edth. Introduzione alla filosofia. Tradução Agnes Bello. Roma: Cittá Nuova, 1998.

STEIN, Edith. La filosofia existencial de Martin Heidegger. Madrid: Editorial Trotta, 2010. 
STEIN, Edith. La struttura della persona humana. Roma: Cittá Nuova, 2000. STEIN, Edith. Obras completas: Escritos filosóficos etapa fenomenólogica. Burgos: Editorial Monte Carmelo, 2005. v. 2.

STEIN, Edith. Sobre el problema de la empatia. Madrid: Editorial Trotta, 2004. STEIN, Edith. Una ricerca sullo Stato. Tradução Agnes Bello. Roma: Cittá Nuova, 1999.

STEIN, Edith. Zum Problem der Eifühlung: inaugural-dissertation. Halle: Buchdruckerei des Waisenhauses, 1917.

WIMMER, Reiner. Vier jüdische philosophinnen: Rosa Luxemburg, Simone Weil, Edith Stein, Hannah Arendt. Tübingen: Attempo Verlag, 1991. 